\title{
A case control study investigating the effects of levels of physical activity at work as a risk factor for prostate cancer
}

\author{
Glenn W Doolan ${ }^{1,5^{*}}$, Geza Benke ${ }^{1}$, Graham G Giles ${ }^{1,2,3}$, Gianluca Severi ${ }^{2,3}$ and Timo Kauppinen ${ }^{4}$
}

\begin{abstract}
Background: A potential risk factor for prostate cancer is occupational physical activity. The occupational aetiology of prostate cancer remains unclear. The purpose of this research was to examine associations between the level of exposure to various measures of physical activity at work and the risk of Prostate Cancer.

Methods: Using the Finnish Job Exposure Matrix and the occupational history of 1,436 cases and 1,349 matched controls from an Australian case control study; we investigated five related exposure variables considered to be risk factors by comparing odds ratios.

Results: Modestly increasing odds ratios were detected with increasing levels of workload but there was no difference in this trend between moderate and high grade tumours. In regard to occupational physical workload no statistically significant association was observed overall but an increasing trend with level of exposure was observed for high grade compared with moderate grade tumours.

Conclusion: Both workload and physical workload merit further investigation, particularly for the latter in relation to grade of tumour.
\end{abstract}

Keywords: Manual handling of burdens, Occupational exposure, Physical activity, Physical workloads, Prostate cancer, Risk factors, Finish job exposure matrix

\section{Background}

Many past studies have investigated various occupational chemical and physical agents as likely causes of prostate cancer [1]. When investigating the causes of death after the diagnosis of prostate cancer it has also been previously found that men with low to moderate grade prostate cancer had a similar rate of death to men without prostate cancer [2]. There are very few well established risk factors of prostate cancer especially those that are potentially modifiable risk factors [3]. Therefore the rationale for this study is to investigate the likely association of some modifiable occupational risk factors and prostate cancer. Previous reported studies investigating the role that physical activity plays in the occupational

\footnotetext{
*Correspondence: 2doolans@vic.australis.com.au

'Department of Epidemiology \& Preventive Medicine, Monash University, The Alfred Centre, The Alfred, Commercial Road, Melbourne, Victoria 3004, Australia

${ }^{5}$ Permanent Address: P.O. Box 276, Trafalgar, Victoria 3824, Australia Full list of author information is available at the end of the article
}

environment, have described physical activity by various metrics $[4,5]$. Ricciardi provided a model for the concept of Sedentarism that included attributes such as expending less than $10 \%$ daily energy in the performance of moderate and high-intensity activities in which the metabolic rate increases at least four times from baseline, or not engaging in physical activities five or more times per week or no leisure activity or no physical activity for up to $3 \mathrm{hrs}$ per week that increases the metabolic rate by four times from base [4]. In relation to Leisure Time Physical Activity (LTPA), Kirk found that those employed in occupations demanding long work hours and low Occupational Physical Activity (OPA) are at higher risk of inactivity.

Some authors [6] have demonstrated that men who participated in regular LTPA reduced their risk for clinical prostate cancer and in the workplace concluded that physical activity at work was also beneficial in reducing the risk of prostate cancer [7-10]. However, Bairati et al. 
suggested that socio-economic status was a probable confounder [10]. In two systematic reviews, it was found that few studies demonstrate a protective role of OPA, even though high levels of OPA and LTPA together seemed to reduce the risk of advanced prostate cancers $[11,12]$. A further review concluded there was inconsistent evidence for an inverse association between OPA and prostate cancer [13]. Recently, a meta-analysis [14] found no clear evidence for an association between job strain and the risk of prostate cancer in relation to OPA. Discacciati et al., adds another dimension to the overall picture by concluding that obesity may have a dual effect on PCa by a decreased risk of low grade PCa and an increased risk of high grade PCa [15].

In contra distinction, a positive association was reported [3] between prostate cancer risk and the highest category of workplace physical activity, which is the opposite of what has been reported by most other studies [7-10] of physical activity and prostate cancer.

Our aim was to investigate whether an association existed between occupational physical activity exposures (assessed using FINJEM ) and prostate cancer, and, in order to address issues of possible detection bias, also to inspect whether such associations differed by grade of tumour. Occupational studies using job exposure matrices (JEMs) have reported some associations with prostate cancer risk, but these have not consistently been replicated by other studies [16]. Although leisure time physical activity may be a limitation and potential cause of bias due to misclassification, there is no reason to suggest that the profile of the cases are different to the controls. This article specifically discusses the reported OPA in men in relation to prostate cancer using the demographic profile of the sample and the odds ratios found in relation to five exposure variables (that are possible risk factors) measuring different forms of workplace physical activity, rather than LTPA. In this study we have used the term 'occupational exposure' to include both ergonomic and psychological variables.

\section{Methods}

Giles et al. [17] has reported on the Australian Prostate Cancer study elsewhere. Briefly, population based cancer registries in Melbourne, Sydney and Perth were utilized to recruit a random sample of 2,528 cases with prostate cancer diagnosed at age 39-80 and 3,125 controls which were considered eligible at the time of selection. For the purposes of this analysis the number of participants was reduced due to factors such as no access to patient records, refusal of controls, insufficient English skills, or moved address. Further analysis was restricted to 1,495 (65\%) cases with prostate cancer diagnosed at age 39-70 and 1423 (46\%) controls aged between 40 and 70 years. The final analysis for which there was sufficient information regarding occupational work histories included 1,436 cases (96\%) and 1,349 (94\%) controls, aged between 39 and 70 years.

Participants were also asked to complete a Lifetime Calender of residence and employment in order to prompt more complete answers when responding to the study questionnaires. The controls were matched through frequency based matching with age and were free of prostate cancer upon recruitment. Recruitment was stratified by age and all men under the age of 60 years were invited to participate. Initially, random samples of $50 \%$ of men aged $60-64$ and $25 \%$ of men aged $65-70$ were selected, with the proportions varying overtime to fit interview quotas.

Cases recruited in Melbourne, Sydney and Perth, Australia were diagnosed in the study period and notified to the population-based cancer registries with a histopathologically-confirmed diagnosis of adenocarcenoma of the prostate, and excluded tumours that were well-differentiated (defined as low grade tumours, that is, those with a Gleason score of less than five).

A major concern with prostate cancer is the diagnostic staging and whether any occupational exposures are associated with medium or high grade cancers. One approach to overcoming concerns regarding the inclusion of clinically unimportant tumours as cases is to select cases who are diagnosed in the study period and notified to the populationbased cancer registries with a histopathologically confirmed diagnosis of adenocarcenoma of the prostate, excluding tumours that are well-differentiated (defined as low grade tumours i.e. those with a Gleason score less than five). This has been addressed in this study.

The self-reported data from the calendar and questionnaires that related to occupation were collated together with date-of-birth, location, children and their gender, and school/occupation and linked with other clinical data variables from study such as smoking, alcohol consumption and physical activity at work. This data was has been shown to be both valid and reliable in other analysis [17].

This further analysis of Giles et al. original study [17] was undertaken using de-identified data and is covered by the AVCC Institutional Ethics Committee permission (1992) from the Anti-Cancer Council of Victoria, and permission from the Chief Investigator of the Risk Factors for Prostate Cancer Case-control Study (2004).

\section{Exposure assessment}

For exposure assessment we used FINJEM [18], a community-based job exposure matrix, originally developed by the Finnish Institute of Occupational Health, for use in epidemiological studies. FINJEM covers a wide range of physical, chemical, microbiological, ergonomic and psychological exposures and is the only job exposure matrix that covers all the different types of radiation. 
FINJEM is coded for 311 classes of occupation, according to the Finnish occupation coding classification. The exposure is measured in line with the method described by Kauppinen at al. [19]. Each job or employment episode of the participants in this study was coded according to the Finnish occupation coding classification and a FINJEM code number (O-Code) was allocated. The coding facilitated the linkage between the occupational activity exposures and prostate cancer status. As an example of this linkage please see Table 1 for a list of the three top occupations with the highest levels of exposures for each exposure variable. It is noted that this list should be treated cautiously as quite a few men had more than one occupation during the course of their working life.

Each exposure variable has a specific definition and value and exposure is characterised by the proportion of exposed workers $(P)$ and the mean level of exposure $(L)$ and is given as $P \times L$ for each occupation. Cumulative exposure was calculated by $\mathrm{P} \times \mathrm{L} \times$ Years exposed in the various exposed jobs reported by the participant. Occupational exposures that did not exceed the non-occupational background level were omitted for example, background radiation levels).

The cumulative exposure for the exposed participants was calculated in tertiles and quartiles. In the model used it included occupational exposure variable plus age, family history and the SEIFA index of economic resources, which is a measure of socio-economic disadvantage, first produced by the Australian Bureau of Statistics [20] following the 1971 census. Only occupational cumulative exposures from our model are presented in the results as it takes into account the level of economic and social disadvantage within the sample, as well as age and family history confounders.

\section{The exposure variables}

We investigated three exposure variables; manual handling of burdens, physical workloads, sedentary work, and two created variables of cumulative activity-over-time and workload by comparing odds ratios in tertiles and quartiles through analysis by binary logistic regression. Moderate and high grade tumours were compared using polytomous regression. The manual handling of burdens consists of lifting, and carrying of heavy burdens, and is an essential feature of the everyday work tasks. Physical workloads consist of tasks where the whole body is exerted by dynamic muscular work. Sedentary work consists of work done in seated posture [19]. Also, one of the variables were created, total cumulative activityover-time is calculated by adding an individual's total scores over their disclosed working life so that some comparison could be undertaken in regard to working in high to low activity jobs for a prolonged period. The psychological exposure variable Workload is a measurement of the overall psychological impact of perceived occupational load over the years of employment. If a subject considers they have been stressed from a high workload over the majority of their working history, it might indicate that, as a stressor, this could have a long-term harmful outcome. Workload is defined as a psychological factor in FINJEM [19] and is derived from the demand to work under tight schedules and time pressure, and to adjust conflicting demands from others subjective perceptions.

\section{Results}

The profile of the sample in Table 2 shows the ages of the participants were relatively evenly spread between cases and controls. In the 65-70 year age group, this group was slightly larger and consistent with the expected occurrence and diagnosis with the control group having the greater number of participants below the age of 55 years.

There were ten percent more Australian born cases than controls. Educationally both groups were closely matched, but numerically the control group had a higher number of men with lower educational attainment. In regard to family history, cases had an $11.2 \%$ greater difference of at least one first degree relative being affected by prostate cancer. Marital status had a similar spread in both groups.

Table 3 shows the results of the binary logistic regression for the five exposure variables, manual handling of burdens, sedentary work, workload, cumulative activityover-time and physical workloads. None of the three ergonomic factors, manual handling of burdens, physical workload and sedentary work were associated with prostate cancer risk, nor was the calculated variable of cumulative activity-over-time. The psychological variable of workload which measures the worker's perceptions in relation to an occupational lifetime of high workload

Table 1 A list of top three occupations with the highest levels of exposures for each exposure variable for men with high grade tumours

\begin{tabular}{llll}
\hline Manual handling of burdens & Sedentary work & Physical workload & Total cumulative activity-over-time \\
\hline Cabinet maker & Taxi driver & Meat worker & Meat worker \\
Meat worker & Truck driver & Cabinet maker & Sailor \\
Market gardener & Draftsman & Cleaner & Policeman \\
\hline
\end{tabular}


Table 2 Demographic description of characteristics of cases and controls

\begin{tabular}{|c|c|c|c|c|}
\hline \multirow{2}{*}{$\frac{\text { Variable }}{\text { Age group }}$} & \multicolumn{2}{|c|}{$\begin{array}{c}\text { Cases } \\
(n=1436)\end{array}$} & \multicolumn{2}{|c|}{$\begin{array}{l}\text { No. of controls } \\
(n=1349)\end{array}$} \\
\hline & $n$ & $\%$ & $n$ & $\%$ \\
\hline 39- 55 & 296 & 20.6 & 329 & 24.4 \\
\hline $55-59$ & 328 & 22.8 & 217 & 16.1 \\
\hline $60-64$ & 359 & 25.0 & 398 & 29.5 \\
\hline $65-70$ & 453 & 31.5 & 405 & 30.0 \\
\hline \multicolumn{5}{|l|}{ Country of birth } \\
\hline Australia & 988 & 68.8 & 816 & 60.5 \\
\hline Not-Australia & 448 & 31.2 & 533 & 39.5 \\
\hline \multicolumn{5}{|l|}{ Educational level } \\
\hline Primary only & 97 & 6.8 & 135 & 10.0 \\
\hline Secondary only & 459 & 32.1 & 426 & 31.7 \\
\hline Post-secondary training & 633 & 44.2 & 581 & 43.2 \\
\hline Tertiary & 243 & 17.0 & 202 & 15.0 \\
\hline \multicolumn{5}{|l|}{ Family history } \\
\hline No first degree relative affected & 1180 & 82.6 & 1257 & 93.8 \\
\hline $\begin{array}{l}\text { At least one first degree relative } \\
\text { affected }\end{array}$ & 249 & 17.4 & 83 & 6.2 \\
\hline \multicolumn{5}{|l|}{ Marital status } \\
\hline Married/de facto & 1230 & 85.8 & 1140 & 85.2 \\
\hline Once married & 159 & 11.1 & 142 & 10.8 \\
\hline Never married & 45 & 3.1 & 65 & 4.0 \\
\hline \multicolumn{5}{|l|}{ State } \\
\hline New South Wales & 419 & 29.2 & 319 & 23.6 \\
\hline Victoria & 767 & 53.4 & 781 & 57.9 \\
\hline Western Australia & 250 & 17.4 & 249 & 18.5 \\
\hline
\end{tabular}

activity was the only statistically significant association and it showed a positive relationship with PCa risk.

Table 4 describes the results of the Polytomous Logistic Regression comparing the associations between moderate and high grade prostate cancers for each of the exposures. No associations were observed for manual handling of Burdens or for Sedentary Work for either moderate or high grade prostate tumour risk.

For total cumulative activity a significant trend in increasing risk was observed for moderate grade but not high grade tumours (heterogeneity $\mathrm{p}=0.06$ ). For workload, both moderate and high grade tumours were positively associated with increasing exposure but were not significantly different in this regard. For physical workload, a statistically significant trend was observed with increasing levels of exposure but only for high grade tumour risk (heterogeneity $\mathrm{p}=0.03$ ).

In this study there were 16,331 reported jobs, providing good variability in job histories for application of FINJEM [21]. The occupational exposure OR's across all of the variables did not vary substantially from the adjustment models for age, family history and SEIFA Index of Economic Resources in both the binary and polytomous logistic regressions.

\section{Discussion}

This study has found that workload is modestly associated with an increased risk of prostate cancer and for both moderate and high grade tumours. This is at odds with the findings of Heikkilä et al. [14] that work related psychological stress is unlikely to be an important factor for prostate cancer. We also found cumulative activityover-time to be modestly associated with prostate cancer risk and showed a small trend with the moderate grade tumours. However, total cumulative activity-over-time appears to have a stronger association with the higher grade tumours. These results suggest that the greater the physical activity in the work place over a long period of time the greater the likelihood of the development of high grade prostate cancer.

In comparison with other studies, our finding regarding total cumulative activity-over-time is contrary to the findings of Bairati [10] where physical activity in the job had an inverse relationship with prostate cancer and they concluded that physical activity was beneficial. Bairati also found that sedentary/light work had a positive association with prostate cancer whereas our findings showed no associations or trends in regard to prostate cancer. The current analysis also does not support the earlier findings by Ricciardi [4] and Kirk \& Rhodes [5] in relation to the combination of OPA and LPTA reduce the risk of advanced prostate cancers. It should be noted that Bairati's study did not use a Job Exposure Matrix, but instead coded the data related to occupational activity using the five levels of physical activity described by the US Department of Labor.

The major strengths of our study are its sample size and the stratification of the subjects to reflect the population of men with and without prostate cancer. With the three main sites we are confident that the study may be generalizable to the population of men in Australia [21].

In Australia, the treatment of Prostate Cancer is very limited outside state capitals, so our sampling frame is unlikely to be a limitation and has not been compromised due to unrepresentative case ascertainment, even though we recruited cases and controls from three major metropolitan centres of the three selected states. The use of FINJEM in Australia has previously been found to be acceptable for various exposures when compared with expert assessment [18].

The principal weakness of our study is the use of a Job Exposure Matrices (JEMs) that can lead to non-differential misclassification of exposure [22], and we would expect non-differential misclassification to have occurred. This will 
Table 3 Cumulative occupational exposures for prostate cancer by binary logistic regression

\begin{tabular}{|c|c|c|c|c|c|c|c|c|}
\hline \multicolumn{9}{|c|}{ Binary logistic regression } \\
\hline Exposure total & Exposure & \multicolumn{2}{|c|}{$\begin{array}{l}\text { Cumulative } \\
\text { exposure }\end{array}$} & Controls & Cases & $\mathrm{OR}^{*}$ & $95 \% \mathrm{Cl}$ & $\mathrm{p}$ for trend (unadjusted model) \\
\hline \multirow{4}{*}{ Manual handling of burdens (score) } & $1^{\text {st }}$ Tertile & 0 & $-\leq 2.654$ & 472 & 534 & 1.00 & & \\
\hline & $2^{\text {nd }}$ Tertile & $>2.655$ & $-\leq 6.808$ & 440 & 443 & 0.96 & $0.79-1.15$ & \\
\hline & $3^{\text {rd }}$ Tertile & $>6.808$ & & 437 & 459 & 1.01 & $0.84-1.22$ & \\
\hline & Continuous & & & 1349 & 1436 & & & 0.82 \\
\hline \multirow{5}{*}{ Sedentary work (score) } & Unexposed & 0 & & 843 & 912 & 1.00 & & \\
\hline & $1^{\text {st }}$ Tertile & $>0$ & $-\leq 1.6$ & 158 & 177 & 0.96 & $0.78-1.25$ & \\
\hline & $2^{\text {nd }}$ Tertile & $>1.6$ & $-\leq 5.108$ & 180 & 161 & 0.78 & $0.62-0.99$ & \\
\hline & $3^{\text {rd }}$ Tertile & $>5.108$ & & 168 & 186 & 1.02 & $0.81-1.29$ & \\
\hline & Continuous & & & 1349 & 1436 & & & 0.94 \\
\hline \multirow{4}{*}{ Work load (score) } & $1^{\text {st }}$ Tertile & $>0$ & $-\leq 102$ & 426 & 366 & 1.00 & & \\
\hline & $2^{\text {nd }}$ Tertile & $>103$ & $-\leq 127$ & 466 & 496 & 1.20 & $0.99-1.46$ & \\
\hline & $3^{\text {rd }}$ Tertile & $>128$ & & 457 & 574 & 1.34 & $1.09-1.65$ & \\
\hline & Continuous & & & 1349 & 1436 & & & 0.001 \\
\hline \multirow{4}{*}{ Total cumulative activity (score) } & $1^{\text {st }}$ Tertile & $>0$ & $-\leq 69$ & 442 & 446 & 1.00 & & \\
\hline & $2^{\text {nd }}$ Tertile & $>69$ & $-\leq 98$ & 455 & 496 & 1.16 & $0.95-1.40$ & \\
\hline & $3^{\text {rd }}$ Tertile & $>98$ & & 452 & 494 & 1.19 & $0.97-1.46$ & \\
\hline & Continuous & & & 1349 & 1436 & & & 0.11 \\
\hline \multirow{4}{*}{ Physical workload (score) } & $1^{\text {st }}$ Tertile & 0 & $-\leq 2.656$ & 456 & 486 & 1.00 & & \\
\hline & $2^{\text {nd }}$ Tertile & $>2.656$ & $-\leq 7.132$ & 448 & 463 & 1.06 & $0.87-1.28$ & \\
\hline & $3^{\text {rd }}$ Tertile & $>7.132$ & & 445 & 487 & 1.15 & $0.95-1.40$ & \\
\hline & Continuous & & & 1349 & 1436 & & & 0.13 \\
\hline
\end{tabular}

*Odds ratios (OR) and associated 95\% confidence intervals $(95 \% \mathrm{Cl})$ adjusted for Age, Family History and SEIFA Index of Economic Resources.

Table 4 Cumulative occupational exposures for prostate cancer by polytomous logistic regression

\begin{tabular}{|c|c|c|c|c|c|c|c|c|c|c|}
\hline \multirow{3}{*}{ Exposure total } & \multicolumn{9}{|c|}{ Polytomous logistic regression } & \multirow{3}{*}{$\begin{array}{c}p-\text {-value } \\
\text { \{heterogeneity }\end{array}$} \\
\hline & \multirow{3}{*}{$\begin{array}{l}\text { Exposure } \\
1^{\text {st }} \text { Tertile }\end{array}$} & \multirow{2}{*}{\multicolumn{2}{|c|}{$\begin{array}{c}\text { Cumulative } \\
\text { exposure }\end{array}$}} & \multicolumn{3}{|c|}{ Moderate grade } & \multicolumn{3}{|c|}{ High grade } & \\
\hline & & & & Cases & $\mathrm{OR}^{*}$ & $95 \% \mathrm{Cl}$ & Cases & $\mathrm{OR}^{*}$ & $95 \% \mathrm{Cl}$ & \\
\hline & & 0 & $-\leq 2.654$ & 446 & 1.00 & & 88 & 1.00 & & \\
\hline \multirow[t]{2}{*}{ Manual handling of burdens (score) } & $2^{\text {nd }}$ Tertile & $>2.655$ & $-\leq 6.808$ & 360 & 0.93 & $0.76-1.12$ & 83 & 1.03 & $0.74-1.44$ & \\
\hline & $3^{\text {rd }}$ Tertile & $>6.808$ & & 372 & 1.01 & $0.83-1.22$ & 87 & 1.08 & $0.77-1.50$ & 0.81 \\
\hline \multirow{4}{*}{ Sedentary work (score) } & Unexposed & 0 & & 750 & 1.00 & & 162 & 1.00 & & \\
\hline & $1^{\text {st }}$ Tertile & $>0$ & $-\leq 1.6$ & 153 & 1.04 & $0.81-1.31$ & 24 & 0.77 & $0.48-1.22$ & \\
\hline & $2^{\text {nd }}$ Tertile & $>1.6$ & $-\leq 5.108$ & 132 & 0.81 & $0.64-1.04$ & 29 & 0.82 & $0.54-1.26$ & \\
\hline & $3^{\text {rd }}$ Tertile & $>5.108$ & & 143 & 0.98 & $0.77-1.29$ & 43 & 1.30 & $0.89-1.89$ & 0.21 \\
\hline \multirow{3}{*}{ Work load (score) } & $1^{\text {st }}$ Tertile & $>0$ & $-\leq 102$ & 312 & 1.00 & & 54 & 1.00 & & \\
\hline & $2^{\text {nd }}$ Tertile & $>103$ & $-\leq 127$ & 409 & 1.21 & $0.99-1.48$ & 87 & 1.36 & $0.94-1.96$ & \\
\hline & $3^{\text {rd }}$ Tertile & $>128$ & & 457 & 1.35 & $1.09-1.57$ & 117 & 1.66 & $1.14-2.41$ & 0.57 \\
\hline \multirow{3}{*}{ Total cumulative activity (score) } & $1^{\text {st }}$ Tertile & $>0$ & $-\leq 69$ & 362 & 1.00 & & 84 & 1.00 & & \\
\hline & $2^{\text {nd }}$ Tertile & $>69$ & $-\leq 98$ & 422 & 1.23 & $1.01-1.50$ & 74 & 0.82 & $0.58-1.16$ & \\
\hline & $3^{\text {rd }}$ Tertile & $>98$ & & 394 & 1.20 & $0.98-1.46$ & 100 & 1.05 & $0.75-1.48$ & 0.06 \\
\hline \multirow{3}{*}{ Physical workload (score) } & $1^{\text {st }}$ Tertile & 0 & $-\leq 2.656$ & 414 & 1.00 & & 72 & 1.00 & & \\
\hline & $2^{\text {nd }}$ Tertile & $>2.656$ & $-\leq 7.132$ & 360 & 0.96 & $0.79-1.17$ & 103 & 1.46 & $1.05-2.04$ & \\
\hline & $3^{\text {rd }}$ Tertile & $>7.132$ & & 404 & 1.14 & $0.94-1.38$ & 83 & 1.22 & $0.86-1.74$ & 0.03 \\
\hline
\end{tabular}

* Odds ratios (OR) and associated 95\% confidence intervals $(95 \% \mathrm{Cl})$ adjusted for Age, Family History and SEIFA Index of Economic Resources. 
almost certainly have led to a bias towards null-effect $(\mathrm{OR}=1)$. Multiple hypothesis testing may produce chance positive results, but we did not find anything significant in this regard. The advantage of using a JEM is that it does not rely on self-reported exposure by subjects potentially leading to differential exposure bias from then cases, which is particularly important for more subjective exposure indices such as workload. Being an objective measure of OPA it overcomes the problem of criterion validity of questionnaires [23]. A second limitation is in not having access to BMI's for the cases and controls, in order to confirm or deny other researchers conclusions [15].

Finally, there would seem to be two contradictory results. Firstly that manual handling of burdens which displayed a slight trend with high grade tumours did not show an association with total prostate cancer. However, Physical workloads did show a small association with total prostate cancer but no association with either moderate or high grade tumours. Therefore there is insufficient evidence to support any causal relationship and it must be concluded that OPA is unlikely to be beneficial in relation to protecting against $\mathrm{PCa}$, even though other studies have suggested that the combination of OPA and LTPA strongly reduced risk $[11,12]$.

\section{Conclusions}

Our findings are in line with other authors recommendations that suggest further research might be merited in regard to workload and physical workload and prostate cancer risk. We recognize, however, that our findings may point to another more definable psychological agent related to stress in the workplace. Given the modest nature of the associations we describe, we provide little evidence to support any causal relationship and conclude that OPA is not proven to be beneficial in relation to protecting against prostate cancer.

\section{Consent}

A written informed consent was obtained from all participating participants in the original study and this further analysis was undertaken on de-identified data.

\section{Competing interests}

The authors declare that they have no conflict of interests.

\footnotetext{
Authors' contributions

GD participated in the design of this investigation, the acquisition of journal articles, analysis and interpretation of data, the drafting of the manuscript and giving the final approval of the version to be published. GB participated in the design of this investigation, in revising the manuscript critically and for important intellectual content, and giving final approval of the version to be published. GG participated in the design of this investigation, the critical revision of the manuscript for important intellectual content, the drafting of the manuscript and giving final approval of the version to be published. GS consulted on the analysis and interpretation of data and giving final approval of the version to be published. TK participated in the design of this investigation, in revising the manuscript critically and for important intellectual content, and giving final approval of the version to be published. All authors read and approved the final manuscript.
}

\section{Funding statement}

The authors received no financial support for the research and/or authorship of this article. The original study of which this further analysis is based was funded by grants from the National Health and Medical Research Council (940394, 991129) and was further supported by funding from Tattersall's and The Whitten Foundation as well as infrastructure provided by The Cancer Council Victoria.

\section{Author details}

${ }^{1}$ Department of Epidemiology \& Preventive Medicine, Monash University, The Alfred Centre, The Alfred, Commercial Road, Melbourne, Victoria 3004, Australia. ${ }^{2}$ Cancer Epidemiology Centre, Cancer Council Victoria, 615 St. Kilda Road, Melbourne, Victoria 3004, Australia. ${ }^{3}$ Centre for Genetic Epidemiology, University of Melbourne, 200 Berkeley Street, Carlton, Victoria 3053, Australia. ${ }^{4}$ Finnish Institute of Occupational Health, Topeliuksenkatu 41aA, FIN-00250 Helsinki, Finland. ${ }^{5}$ Permanent Address: P.O. Box 276, Trafalgar, Victoria 3824, Australia.

Received: 14 January 2014 Accepted: 25 July 2014

Published: 7 August 2014

\section{References}

1. Ilic M, Vlajinac $H$, Marinkovic J: Case-control study of risk factors for prostate cancer. Br J Cancer 1996, 74:1682-1686.

2. Ketchandji M, Kuo YF, Shahinian V, Goodwin JS: Cause of death in older men after the diagnosis of prostate cancer. J Am Geriatr Soc 2009, 57:24-30.

3. Sass-Kortsak AM, Purdham JT, Kreiger N, Darlington G, Lightfoot NE, Sass K: Occupational risk factors for prostate cancer. Am J Ind Med 2007, 50:568-576.

4. Ricciardi R: Sedentarism: a concept analysis. Nurs Forum 2005, 40:79-87.

5. Kirk MA, Rhodes RE: Occupation correlates of adults' participation in leisure-time physical activity: a systematic review. Am J Prev Med 2011 40(4):476-485.

6. Barnard R, Shan-Leung P, Aronson WJ, Cohen P, Golding LA: A mechanism to explain how regular exercise might reduce the risk for clinical prostate cancer. Eur J Cancer Prev 2007, 16:415-421.

7. Lagiou A, Samoli E, Georgila C, Minaki P, Barbouni A, Tzonou A, Trichopoulos D, Lagiou P: Occupational physical activity in relation with prostate cancer and benign prostatic hyperplasia. Eur J Cancer Prev 2008 17:336-339.

8. Strom SS, Yamamura Y, Flores-Sandoval FN, Pettaway CA, Lopez DS: Prostate cancer in Mexican-Americans: identification of risk factors. Prostate 2008, 68:563-570.

9. Krishnadasan A, Kennedy N, Zhao Y, Morgenstern H, Ritz B: Nested casecontrol study of occupational physical activity and prostate cancer among workers using a job exposure matrix. Cancer Causes Control 2008, 19:107-114.

10. Bairati I, Larouche R, Meyer F, Moore L, Fradet Y: Lifetime occupational physical activity and incidental prostate cancer (Canada). Cancer Causes Control 2000, 11:759-764.

11. Anzuini F, Battistella A, Izzotti A: A Physical activity and cancer prevention: a review of current evidence and biological mechanisms. J Prev Med Hyg 2011, 52(4):174-180.

12. Liu YP, Hu FL, Li DD, Wong F, ZHU L, Chen WY, Ge J, An R, Zhao Y: Does physical activity reduce the risk of prostate cancer? A systematic review and meta-analysis. Eur Urol 2001, 60:1029-1044.

13. Doolan G, Benke G, Giles GG: An update on occupation and prostate cancer. Asian Pac J Cancer Prev 2014, 15:501-516.

14. Heikkilä K, Nyberg S, Thorell T, Alfredsson L, Bjorner JB, Bonenfant S, Borritz M, Bouillon K, Burr H, Dragano N, Geuskens GA, Goldberg M, Hamer M, Hooftman WE, Houtman IL, Joensuu M, Knutsson A, Koskenvuo M, Koskinen A, Kouvonen A, Madsen IE, Magnusson Hanson LL, Marmot MG, Nielsen ML, Nordin M, Oksanen T, Pentti J, Salo P, Rugulies R, Steptoe A, et al: Work stress and risk of cancer: meta-analysis of 5700 incident cancer events in 116,000 European men and women. BMJ 2013, 346:165.

15. Discacciati A, Orsini N, Wolk A: Body mass index and incidence of localized and advanced prostate cancer-a dose-response meta-analysis of prospective studies. Ann Oncol 2012, 23(7):1665-1671.

16. Weston TL, Aronson KJ, Siemiatycki J, Howe GR, Nadon L: Cancer mortality among males in relation to exposures assessed through a job-exposure matrix. Int J Occup Environ Health 2000, 6:194-202. 
17. Giles GG, Severi G, McCready MR, English DR, Johnson W, Hopper UL, Boyle P: Smoking and prostate cancer: findings from an Australian casecontrol study. Ann Oncol 2001, 12:761-765.

18. Benke G, Sim M, Fritschi L, Aldred G, Forbes A, Kauppinen T: Comparison of occupational exposure using three different methods: hygiene panel, job exposure matrix (JEM), and self reports. Appl Occup Environ Hyg 2001, 16:84-91.

19. Kauppinen T, Toikkanen J, Pukkala E: From cross-tabulations to multipurpose exposure information systems: a new job-exposure matrix. Am J Ind Med 1998, 33:409-417.

20. ABS: An Introduction to Socio-Economic Indexes for Areas (SEIFA) Australia 2006 (Preliminary). In Australian Bureau of Statistics. Canberra, Australia: Commonwealth of Australia; 2006.

21. Breslow NE, Day NE: Statistical methods in cancer research: Vol II - The design and anallysis of cohort studies. Lyon, France: IARC Scientific Publications; 1987:82-297.

22. Bouyer J, Dardenne J, Hemon D: Performance of odds ratios obtained with a job-exposure matrix and individual exposure assessment with special reference to misclassification errors. Scand I Work Environ Health 1995, 21:265-271.

23. Kwak L, Proper Kl, Hagstömer M, Sjöström M: The repeatability and validity of questionnaires assessing occupational physical activity-a systematic review. Scand J Work Environ Health 2011, 37(1):6-29.

doi:10.1186/1476-069X-13-64

Cite this article as: Doolan et al:: A case control study investigating the effects of levels of physical activity at work as a risk factor for prostate cancer. Environmental Health 2014 13:64.

\section{Submit your next manuscript to BioMed Central and take full advantage of:}

- Convenient online submission

- Thorough peer review

- No space constraints or color figure charges

- Immediate publication on acceptance

- Inclusion in PubMed, CAS, Scopus and Google Scholar

- Research which is freely available for redistribution 